\title{
VIRTUAL LEARNING MODULES FOR TRAINEES
}

\author{
Heike Köppe \\ Höxter Business Schools, Germany. mail@heike-koeppe.de
}

\begin{abstract}
Even technically inexperienced teachers can create some of their own virtual training units with this most practical tool for everyday teaching use. Previous e-learning solutions have not as yet been able to meet the demand for selfdeveloped tasks that suit the requirements of a particular learning group and this was the reason for this project coming into being. The tasks, as in the later final examination, are based on a number of pre-defined types such as multiple-choice tests, true/false and gap texts. The tool is suitable not only for individual exam practice by the student but also for doing automatically evaluated tests in the lesson situation. The tasks are available either on CD or in the Internet as required. Since its conception this learning system has met with a high degree of approval among teaching staff by way of its ease of application. After regular use in foreign language teaching a significant improvement in student performance has been noted.
\end{abstract}

Keywords: vocational education, authoring systems, tools, learner centred learning

\section{MOTIVATION}

E-learning was intended to be introduced at the BKH Business School in Höxter within the Qualifying and Vocational Training Network Framework of the QBN. In which phases of lessons can such learning software be employed with the greatest efficiency? There are probably numerous examples of software-supported treatments of certain lesson topics for selfstudy, including the basics of a given subject. But what we (the QBN-team) are basically considering here is enhancing class teaching with additional learning materials. The target groups are students in sometimes extremely heterogeneous groups that have to be introduced to this new learning method slowly for pedagogical reasons. 
An analysis of teaching processes in the situation here given (cf. Dick, 2000) shows that one would not be inclined to employ an e-learning system either for the introduction, or for general work, on most lesson topics. On the other hand, it can be helpful in marking and evaluation. We would expect that e-Learning would account for at most $25 \%$ of lesson times. Recent research by Breuer $(2002 ; 2003)$ would imply that up to $40 \%$ of the learning process could be covered by an e-Learning system. One of the key areas here would be in the Breuer's third phase, i.e. in the more detailed treatment of lesson topics that the students are, in principle, already converse with, and the learning group as a whole should be accustomed to this way of learning. Breuer would also expect a lesson share of around $25 \%$ in the implementary phase of an e-Learning system. However, not only the learning group, but also the teacher, must first become accustomed to such a system.

In order to achieve as high a degree of acceptance as possible among staff, we use a system at a point where it can best be integrated into the standard teaching culture. This was a determining factor with regard to its contents. The learning system should be such as to prepare the students for examinations regardless of time or place considerations, and to be able to 'fill in' any gaps in their knowledge. It should also be of assistance to students in addressing typical learning difficulties. Also, the teacher's workload should be reduced in these lessons.

One important requirement of a learning program for use in school lessons is that it is in harmony with the teacher's own teaching concepts, practises and beliefs. It should be able to meet the needs of each of the students, their age, the academic level of the class, as well as any learning difficulties, but at the same time correspond to the teaching style and the choice of material made by the teacher. A purely subject-matter oriented approach would not be flexible enough. The teaching process is designed flexibly so as to meet the needs of each learning group with the same teacher based on the same subject matter.

A learning program that exactly meets the needs of each pupil, their learning difficulties, the teaching style, the teacher's choice of topics and the age of the pupils does not exist. For example, a mathematics program from the well-known Klett Publishing Co. in Germany introduces differential calculus with the acceleration problem of a ball on a sloping surface. Such an approach would be of little sense in a business-oriented college. Foreign language programs at advanced levels, in particular, do not presuppose a level of previous knowledge that suits a given learning group and programs for language beginners are mostly too child-like.

In evaluating a wide variety of commercial learning software we could not find a CMS/LMS system, that was on the one hand sufficiently simple to work with, so as to be acceptable even to sceptical and technically 
inexperienced staff, and on the other hand be flexible enough to fulfil the pedagogical requirements, for example, by providing learning aids for typical learning difficulties. This is why we developed our own learning system.

In the following section I will describe the demands with regard to content placed on the system and its technical implementation, the results, evaluation and future possibilities of application and development.

\section{IMPLEMENTATION}

\subsection{Contents concept}

The contents of the e-learning system were based on the commercial clerks examination for business vocations (Kaufmannsgehilfenprüfung für kauf-männische Ausbildungsberufe). This meant that it was directly related to didactical considerations at the Höxter Business College. The direct relation to practical needs and its usefulness in day-to-day teaching, both for the students for the teachers, were key factors in making this decision.

The system should be capable of being employed in two ways: firstly as a training system, and then also as a test system. Key features of the training tasks are tips, explanations, feedback, hot words and learning aids. In the test system the student receives no responses when doing the work, on the contrary the teacher receives a performance overview after the test and can thus quickly and easily ascertain the level of knowledge of the class. (Fig. 1)

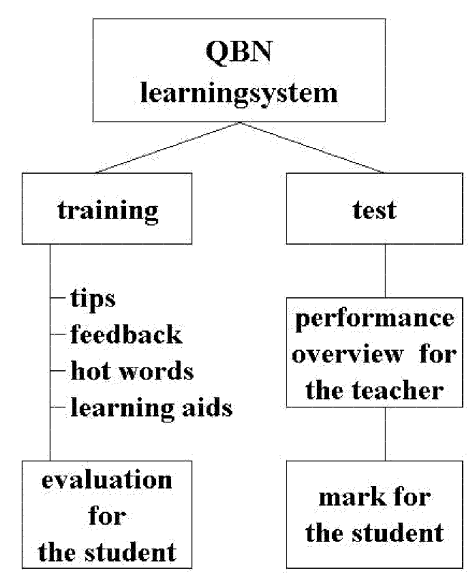

Figure 1. Structure of the system 
The types of tasks were developed on the basis of 'multiple choice - 1 of n', 'true/false' and 'gap text' tests. The necessary task structure was developed together with a group of teachers of various subjects. The form of the multiple-choice tasks was developed in line with the later official final examination. Feedback was provided as a learning aid to each possible incorrect answer. In addition, the student can also call up one or two further learning tips and a sample answer (Fig. 2). Another variation is especially suitable for teaching foreign languages.

The evaluation of the performance level is done automatically. The evaluation system was developed by several teachers on a practical basis and it can subsequently be adapted to changing needs. Better assessment of one's own performance and learning aids that can be controlled individually in the course of working with them all motivate the students towards training with a definite aim in mind.

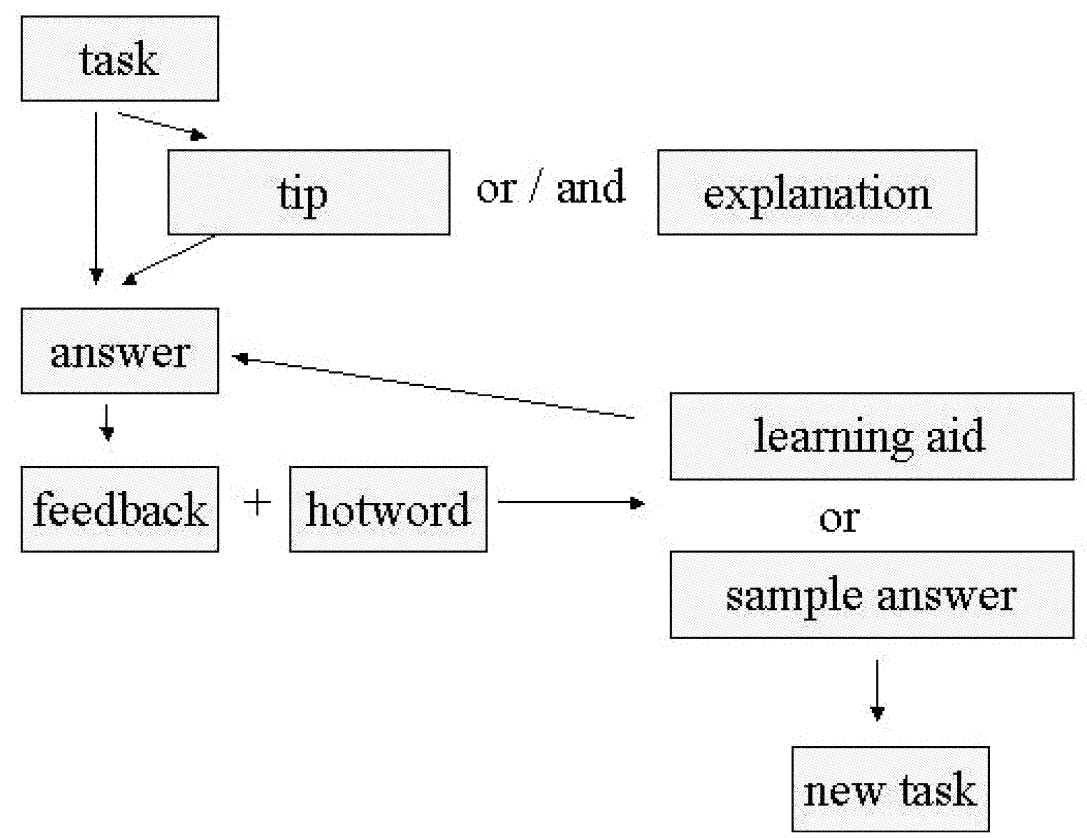

Figure 2. Logical structure of an exercise for training

Fully functional Excel tables that demand student creativity can also be integrated into the mathematics/economics tasks. The pedagogical value of 
this type of task is considerably enhanced since the student is given the chance and the stimulus to experiment with any number of variants. (Fig. 3)



Figure 3. Added Excel sheet

\section{$2.2 \quad$ Technical concepts}

We used an authoring system in preference to individual programming in creating the learning software. An authoring system is simpler to operate whilst still being capable of allowing for individual wishes. Because of its versatility and its widespread use in school and industry we chose the Toolbook authoring system. In order to facilitate the exchange of tasks and exercises among staff by way of a uniform structure, and to overcome obstacles in its application, we created an easy-to-use editor for those with little computer experience, with which teachers can produce and organise exercises and help texts. Entry masks are adapted to suit the various types of exercises. Enter errors are automatically detected by special routines.

Exercise/task texts that have been produced can be used both for a test system as well as for a training system. This means that a large number of staff can concentrate on the pedagogical aspects of the job in hand, while a comparatively small team deals with programming itself. The editor was developed so as to enable all staff to work with the free Runtime version of Toolbook. The general availability and easy operation of the editor and the templates also mean that it is possible to produce exercises directly in lessons. The pupils can use the tools to produce their own exercises. This 
means, for example, that the pupils can produce exercises based on their mistakes instead of just doing corrections for their tests. In order to be able to provide suitable learning aids and tips on typical learning difficulties, they have to think the theme over much more carefully than was previously the case.

\begin{tabular}{|c|c|}
\hline Solution &  \\
\hline Header & $\exists$ \\
\hline Task & $\exists$ \\
\hline Explanation & 븐 \\
\hline Hint & $\overrightarrow{7}$ \\
\hline Answ. 1 & 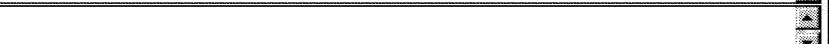 \\
\hline Answ. 2 & تص \\
\hline Answ. 3 & 근 \\
\hline Answ. 4 & a \\
\hline FB 1. & 교 \\
\hline FB 2 & $\Rightarrow$ \\
\hline FB 3 & $\Delta$ \\
\hline$\overline{\mathrm{FB} 4}$ & $\Rightarrow$ \\
\hline HW 1.1 & $\Delta$ \\
\hline
\end{tabular}

Figure 4. Editor segment, mask for a foreign language exercise

Teachers' and pupils' wishes were better able to be put into practise in a number of follow-up versions of the e-learning system due to the close interplay between programming and evaluation in the application phase.

\section{THE ROAD MAP}

With regard to its use in schools, we tried to considerably extend the current number of users - at present around 25, i.e. about half of the staff. Exchanging exercises between staff members is still encouraged, as is the already well-advanced collection of a large reserve of exercises. As of today there are more than 1000 exercises based on various templates that currently find use in lessons in the final year groups in the part-time 'dual system' vocational courses and in all full-time classes, with a total of more than 400 students. Training in foreign language courses and performance tests are the 
preferred applications at the moment. Selected training units for preparing for all external Chamber of Commerce final examinations are available.

In the long term, practice phases can be given as homework exercises. Subject matter can be didactically prepared so that students may work on certain topics independently. This is the aim of the project 'Fachschule (College) Online'. In everyday teaching, this would enable us to integrate elearning into the 'introduction to the problem' and 'solution-finding' phases.

With the proposed technical system development, it will be possible to automatically integrate text based content matter, pictures, videos, Excel tables and PowerPoint animations into the template. The enhancement of the test system ' 1 of $n$ ' to an ' $x$ of $n$ ' type is soon to be completed - a test system with automatic evaluation.

\section{RESULTS AND CONCLUSION}

The e-learning project was successfully carried out at the BKH Business School, resulting in easy to use learning software. This software has proven itself in everyday use, and is employed in training and in performance tests. CBT was used for homework exercises in the weaker of two industrial clerk course groups (cf. Gregor, 2003). Students were thus more motivated and took a more active part in lessons as a result of their feeling more versed in the subject matter. Examination results showed that the weaker class had almost made up for the previously existent difference in performance.

\section{REFERENCES}

Breuer, J. (2002). Makrodidaktisches Design einer telekommunikationsunterstützen Weiterbildungsmaßnahme: Kombination von Präsenz- und Telelernphasen. In: F. H. Esser, M. Twardy, \& K.Wilbers (Eds.), e-Learning in der Berufsbildung. (pp. 215-221) Köln,.

Breuer, J. (2003). Blended Learning? Der Mix von Präsenz- und E-Learning-Phasen unter besonderer Berücksichtigung des Kommuniaktionsverhaltens der Dozenten in einer ELearning-Maßnahme. In: F. H. Esser \& M. Twardy, M.(Eds.), Abschlussveröffentlichung zum Modellversuch (pp.5) Köln: MERCUR

Dick, E. (2000). Multimediale Lernprogramme und telematische Lernarrangements, Einführung in die Didaktische Gestaltung, Bildung und Wissen.

Gregor, M. (2003). M.A. thesis, unpublished, Höxter Business College. 


\section{BIOGRAPHY}

Heike Köppe, born 1963, studied Mathematics, French and Education Studies in Bielefeld and Neuchâtel. She has been teaching at the BKH (Höxter Business College) for 8 years. She took over the project management and the programming for the virtual learning modules. 